\title{
Osteopathic research: The needed paradigm shift
}

\author{
IRVIN M. KORR, PhD
}

Among the osteopathic medical profession's most conspicuous achievements of the past 20 years has been the threefold expansion of its very source - the colleges of osteopathic medicine-from 5 to 15,10 of them universityaffiliated and publicly funded. As a result, the osteopathic medical profession has been recognized as the nation's fastest growing profession. No less important is the fact that in the process it has succeeded in recruiting a corps of competent scientists, more than three times larger than that of 20 years ago, to serve as teachers of osteopathic physicians and as researchers in the basic medical sciences. This has presented the osteopathic medical profession with the opportunity for a proportionate increase in the scale and scope of its research productivity.

There has been such an expansion of research under osteopathic auspices, much of which has brought wide recognition to the investigators and their institutions. There has been little increase of research, however, in areas most relevant to osteopathic theory and practice, and designed to test and refine the theory and improve the effectiveness of practice. There are valid reasons, of course, why scientists are loathe to depart-and should not depart-from fields for which they prepared, in which they have established themselves and become productive, widely recognized, and successful in procuring grants in order to seek answers to osteopathic questions. Nevertheless, it has been both disappointing and perplexing that so few have found challenge and excite-

Reprint requests to Irvin M. Korr, PhD, 740 Oakwood Trail, Ft Worth, TX 76112. ment in the hundreds of questions waiting to be asked and addressed that have arisen from osteopathic thought, prior research, and a century of clinical observation and experience.

Two main reasons (aside from the prior commitments just identified) have emerged from inquiries of many colleagues over many years. First is the misperception that "osteopathic" research is limited to investigation of the "distinctive" modality, manipulative treatment; and that if one's skills are in areas not directly related to the musculoskeletal system, one has no contribution to make.

Second is the general impression that osteopathic principles, as customarily presented-the body is a unit; the body has inherent self-regulatory, defensive, and recuperative powers; structure and function are reciprocally related, etc-are so self-evident, axiomatic, implicit, and pervasive in biomedical research as to be too platitudinous to raise new questions for research.

This article is addressed to these misperceptions. Its purposes are as follows: (1) to restate and elaborate the familiar osteopathic principles from my viewpoint as a physiologist in such a way as to make more evident their theoretical implications and to evoke the latent questions; (2) to identify, on the basis of the elaborated principles, some of the areas awaiting exploration; and (3) to indicate the kinds of investigative strategies - paradigms - that seem to be called for. In the concluding section, I shall more briefly examine the implications of these principles, as restated, to the testing of the effectiveness of osteopathic medical care.

(continued on page 161) 


\section{Lowering Cholesterol Is Important...}

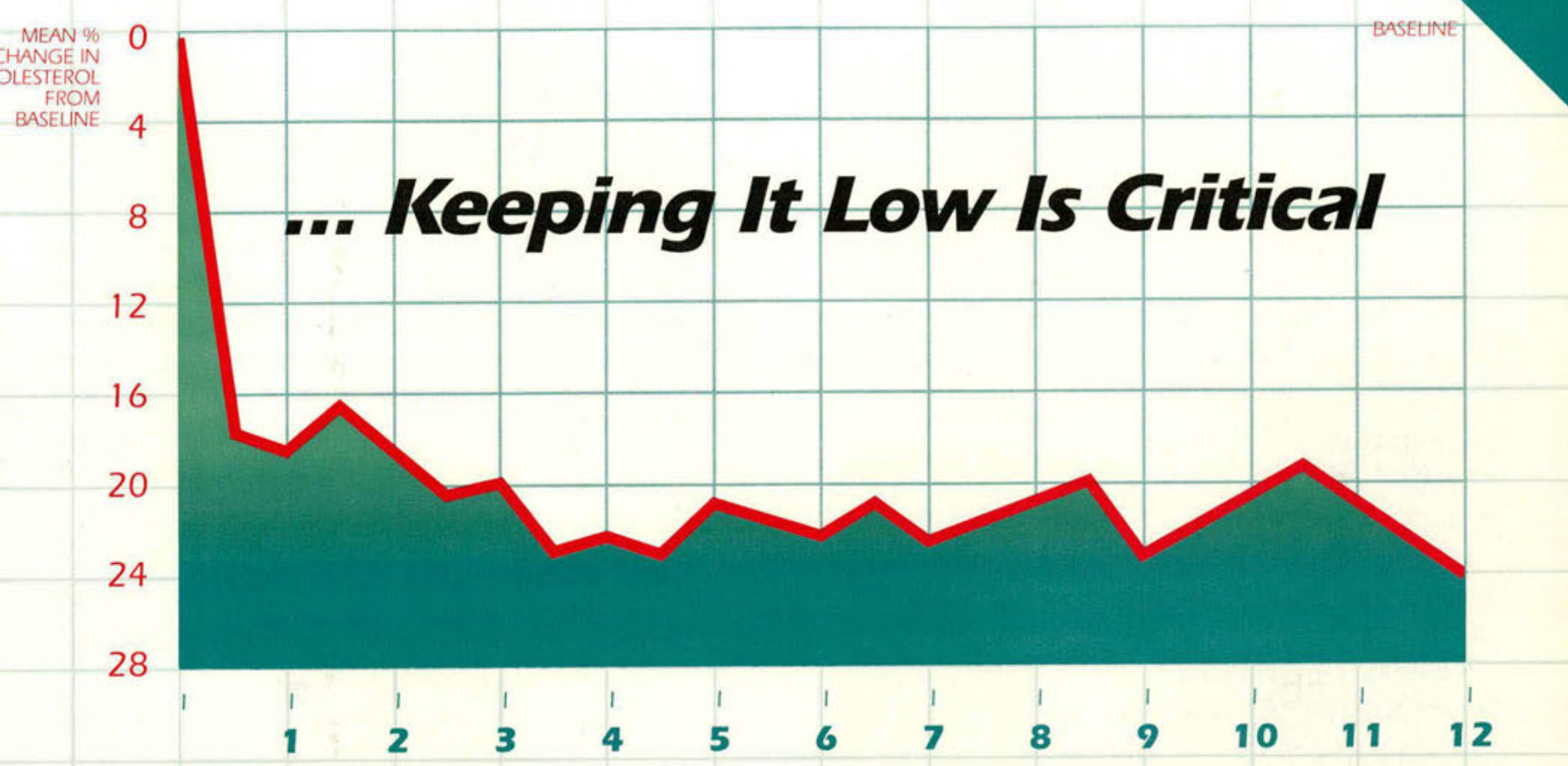
YEARS OF
LORELCO
Long-term Efficacy of Lorelco Demonstrated in Combined TREATMENT
Studies of 117 Patients Followed Over a 12-Year Period 1

\section{Effective Monotherapy*}

- Enhances the clearance of LDLcholesterol from the bloodstream

\section{Excellent Patient Compliance}

- Well tolerated and convenient; one 500-mg tablet bid with meals

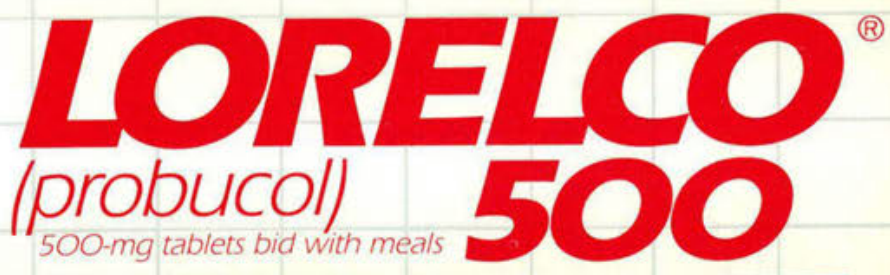

The future of cholesterol control 



\section{Lorelco ${ }^{\circledR}$ Tablets (probucol)}

CAUTION: Federal law prohibits dispensing without prescription.

DESCRIPTION: Loreico (probucol) filim-coated tablets for oral administration contain $250 \mathrm{mg}$ or $500 \mathrm{mg}$ of probucol per tablet
Each tablet also contains as inactive ingredients corn starch, ethyicellulose, glycerin, hydroxyprogy cellulose, hydroxyprogy Each tabiet also contains as inactive ingredients: corn starch, ethyicellulose. glycerin, hydroxypropyl cellulose, hydroxyprop:

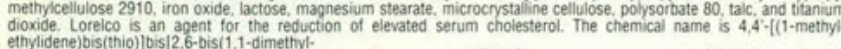
ethyl) phenol]. Its chemical structure does not

resembie that of any other avalable cholesterol-

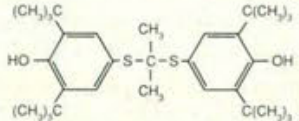

CLINICAL PHARMACOLOGY:Lorelco lowers total serum cholesterol and has relatively little effect on serum triglycerides. Patients
responding to probucol exhibita decrease in low-density lipoprotein (LDL) cholesterol. Cholesterol is reduced not only in the LDL responding to probucol exhibita a decrease in low-density lipoprotein (LOL) cholesterol. Cholesterol is reduced not only in the LDL
fraction, but also in the high-density lipoprotein (HOL) fraction with proportionately greater effect on the high-density portion

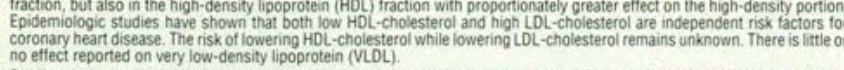

Studies on the mode of action of Lorelco indicate that $t$ increases the fractional rate of $L D L$ catabolism. This effect may be linked
to the observed increased excretion of fecal bile acids, a final metabolic pathway for the elimination of cholesterol from the body. to the observed increased excretion of fecal bile acids. a final metabolic pathway for the elimination of cholesterol from the body.
Lorelco also exhibits inhibition of early stages of cholesteral biosynthes is and s sight thinisition of absorption of dietary cholesterc There is no increase in the cyclic precursors of cholesterol, namely desmosterol and 7-dehydrocholesterol. On this basis, it is

Absorption of Lorelco from the gastrointestinal tractis limited and vartabie. When $i$ is administered with food, peak blood leveis

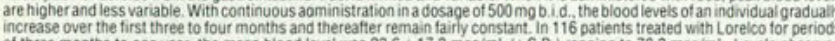

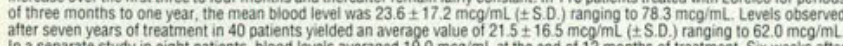
In a separate study in eight patients, blood leveis averaged $19.0 \mathrm{mco} / \mathrm{mL}$ at the end of 12 months of tre
cessation of therapy, the average had tallen by $60 \%$. After six months, the average had tallen by $80 \%$. In December 1984, a National Institutes of Health Consensus Development Conference Panel' concluded that lowering definitely
elevated blood cholesterol levels (specifically blood levels of LDL-cholesterol) will reduce the risk of heart attacks due to coronary
heart disease. The effect of probucol-induced reduction of serum choiesterol or trighyceride levels. of reduction of $\mathrm{HDL}$ heart disease. The effect of probucol-induced reduction of serum cholesterol or triglyceride levels. or reduction of HDL-
cholesterol levelis on morbidity or mortality due to coronary heart disease has not been estabilished. INDICATIONS AND USAGE: Serious animal toxicity has been encountered with probucol. See WARNINGS and ANIMAL.
PHARMACOLOGY AND TOXICOLOGY sections. Probucol is not an innocuous drug and strict attention should be paid to the INDICATIONS, CONTRAINDICATIONS, and WARNINGS.

Drug therapy should not be used for the routine treatment of elevated blood lipids for the prevention of coronary heart disease Dietary therapy specific for the type of hyperi.ipidemia is the initial treatment of choice. Excess body weight may be an importan Tactor and should be addressed prior to any drug therapy. Physical exercise can be an important ancilary measure. Contributory
disease such as hypothyyoidism or diabetes mellitus should be looked for and adequately treated The use of drugs should be
considered only when reasonable attempts have been made to obtain satistactory results with nondrug methods. If the decision

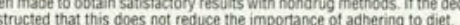

The selection of patients for cholesterol-lowering drug therapy should take into account ther important coronary risk factors tactors for each of the cholesterol-lowering drugs prior to selecting the one most appropriate for an individual patient

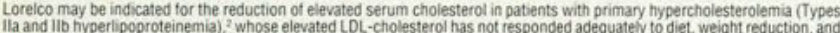

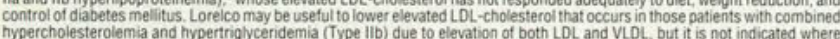
hypercholesterolemia and hypertrigycenidemia (Type llb) due to elevation of both LDL and VLDL, but it is not indicated where
hypertriglyceridemia is the abnormality of mostconcern. Atter establishing that the elevation in serum total cholesterol represents pid disorder, it should be determined that patients being considered tor treatment with Lorelco have anoievated $10 \mathrm{~L}$. cholesterol as the cause for an elevated total serum cholesterol. This may be particularly felevant for patients with elevate
triglycerides or with markedly elevated HDL-cholesterol values. where non-LDL fractions may contribute signficantly to tota cholesterol levels without apparent increase in cardiovascular risk. in most patients, LDL-cholesterol may be estimated LDL - cholesterol $=$ Total cholesterol $-[(0.16 \times$ triglycerides $)+$ HDL-cholesterol]

When total triglycerides are greater than $400 \mathrm{mg} / \mathrm{dL}$, this equation is less accurate. In such patients, LDL-cholesterol may be It is not awways possibie to predict from the lipoprotein type or other factors which patients will exhibit favorable results. Lipid

The effect of probucol-induced reduction of serum cholesterol or triglyceride levels, or reduction of HDL-cholesterol levels on morbidity or mortality due to coronary heart disease has not been estabishec.

CONTRAINOICATIONS: (See also WARNINGS and PRECAUTIONS.) Lorelco is Contraindicated in patients who are known to have suggestive of serious ventricular artrictithmias or with unexplained syncope of syncope of cardiovascular origin.
lorelco is contraindicated in patients with an abnormally long QT interval. WARNINGS: SERIOUS ANIMAL TOXICITY HAS BEEN ENCOUNTERED WITH PROBUCOL IN RHESUS MONKEYS FED AN

Prolongation of the OT interval can occur in patients on Lorelco. Serious arthythmias have been seen in association with an abnormally long ar interval in patients on Lore
The following precautions are deemed prudent:

Patients should be advised to achere to a low cholesterol. low fat diet at the start of treatment with Lorelco and throughout

2. An ECG should be done prior to startingtreatment and repeated araperoprate ind long QT interval is observed, the possible benefits and risks should be carefully considered before making a decision to
continue Lorelco. Lorelcot therapy should be discontinued or not started it the QT interval at an observed heart rate on a resting ECG is persistently
more than one of the values listed below. OT Interval in $\sec (15 \%$ above
the upper limit of normal)

\begin{tabular}{ccc}
\multirow{2}{*}{$\begin{array}{c}\text { Observed Heart Rate } \\
\text { (beats/min) }\end{array}$} & \multicolumn{3}{c}{ the upper limit of normal) } \\
\cline { 2 - 3 } & Males & Females \\
\hline 40 & 0.56 & 0.58 \\
50 & 0.52 & 0.53 \\
60 & 0.49 & 0.50 \\
70 & 0.45 & 0.47 \\
80 & 0.43 & 0.44 \\
86 & 0.42 & 0.43 \\
92 & 0.40 & 0.41 \\
100 & 0.39 & 0.40 \\
109 & 0.37 & 0.38 \\
120 & 0.36 & 0.36 \\
133 & 0.34 & 0.35
\end{tabular}

(Table 6).

3. Patients developing unexplained syncope or syncope of cardiovascular origin should have Lorelco therapy discontinued and

4. Drugs that prolong the OT interval are more likely to be associated with ventricular tachycardia after:

. Addition of a second drug that prolongs the OT interval (including tricyclic antidepressants, class I and III antiarrtythmics.

d. Severe bradycardia due to intrinsic heart disease or drug effects on the atrial rate (beta-blockers) or AV block (digoxin).

e. Development of recent or acute myocardial infarction, ischemia, or inflammation. The use of Lorelco in patients receiving any of these drugs should be based on the conclusion that alternate methods of
hypocholesterolemic therapy are either ineffective or not tolerated, and the potential benefits of cholesterol lowering
outweigh the risk of serious arrhylhmia.

The following conditions should be resolved or corrected prior to initiation of therapy with Lorelco

a. Hypokalemía

b. Hypomagnesemia

. Pecent or acute myocardiatrinsic heart disease or drug effects on the atrial rate (beta-blockers) or AV block (digoxin). PRECAUTIONS

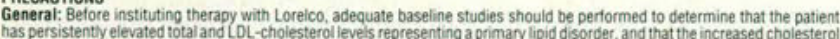
has persistentily elevated total and $\mathrm{LL} L$-cholesterol levels representing a primary lipid disorder, and that the increased cholestercl nephrotic syndrome, or dysproteinemias. Serum lipid levels, including HDL-cholesterol, should be determined after an overnight
fast before treatment, durning an adequate trial of diet and weight reduction therapy prior to addition of drug therapy, and periodically during combined diet and drug therapy, including assessment during the first several months of drug treatrment. A

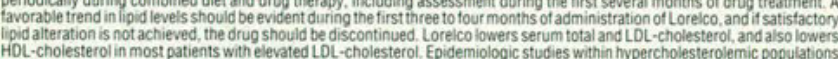
$\mathrm{HOL}$-cholestero in most patients with elevated LDL-cholesterol. Epidemiologic studies within hypercholesterolemic populations
have shown that serum HDL-cholesterol is an independent, inversely correlated, risk tactor for coronary heart disease (see have shown that serum HDL-cholesterol is an independent, inversely correlated, risk factor for coronary heart disease (see
CLINICAL PHARMACCLOGY. Human studies which will attempt to confirm or deny the hypothesis that drug-induced anteratio of serum HDL -cholesterol will aftect cardiovascular risk since no long-term. controlled clinical trials of Lorecelco for the prevention

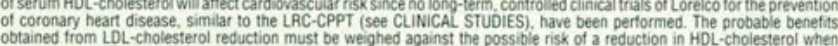
obtained from LDL-cholesterol reduction must be weighed against the possible risk of a reduction in $\mathrm{HDL}$-cholesterol when
asseessing the response of each patient receiving Lorelco treatment. If satisfactory lipid alteration is not achieved. the drug should
be discontinued.
Information for Patients: The patient should be instructed to adhere to a prudent diet Females should be cautioned against
becoming pregnant for at least six months after discontinuing Lorelco and should not breast-teed their intants during therapy Laboratory Tests: The physician should schedule periodic blood lipid determinations and periodic ECGs. (See WAANINGS.

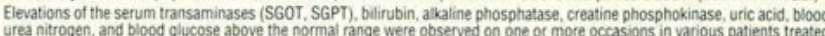
urea nitrogen, and blood glucose above the normal range were observed on one or more occasions in various patients treated
with Lorelco. Most often inese were transient and/or could have been related to the patient's clinical state or other modes of of these are drug reiated cannot be excluded In controlied trials the incidence of abnormal laboratory values was no higher the patients treated with Lorelco than in the patients who received placebo. If abenormal laboratory tests persist or worssen, if clinical
signs consistent with the abnormal laboratory tests develop, or if systemic manitestations occur. Lorelco should be discontinued Orug Interactions: The addition of clofibrate to Lorelico is not recommended, since the lowering effect on mean serum levels of
either LLL oo total cholesterol is generally not significantly additive and, in sorne patients, there may be a pronounced lowering
of $H D L$-cholesterol.

Neither oral hypoglycemic agents nor oral anticoagulants alter the effect of Lorelco on serum cholesterol. The dosage of these

Monkeys fed a high fat. high cholesterol diet admixed with probucol exhibited serious toxicity. (See WARNINGS and ANIMAL
PHARMACOLOGY AND TOXICOLOGY sections) Prolongation of the OT internal Ian occir in patients On Lorelco and serious

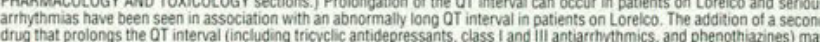
drug that prolongs the OT interval (including tricyclic antidepressants class I and III ant

Carcinogenesis, Mutagenesis, Impairment of Fertility

In chronic studies of two years' duration in rats, no toxicity or carcinogenicity was observed. These results are consistent with Pregnancy
Teratogenic Effects

Pregnancy - Category B: Reproduction studies have been pertormed in rats and rabbits at doses up to 50 times the human dose
and have revealed no evidence of impaired fertility or harm to the tetus diue to probucol. There are, however, no adequate anse well-controlled studies in pregnant women. Because animal reproduction studies are not always predictive of human response, this drug should be used during pregnancy only it clearly needed. Furthermore, if a patient wishes to become pregnant, it is
recommended that the drug be withdrawn and birth control proceddures be used for at least six months because of persistence
of the drug in the body for prolonged periods. (See CLINICAL PHARMACOLCGY.)

Labor And Delivery: The effect of Lorelco on human labor and delivery is unknown

Nursing Mothers: It is not known whether this drug is excreted in human milk, but it is likely, since such excretion has been shown. Pediatric Use: Safety and effectiveness in children nave not been established.

ADVERSE REACTIONS

Gastrointestinal

diarthea or loose stools, flatulence, abdominal pain, nausea, vomiting, indigestion, gastrointestinal bleeding

Cardiovaseular

prolongation of the QT interval on ECG, syncope, ventricular arrhythmias (ventricular tachycardia, torsades de pointes.
ventricular fitiorilation), sudden death

Neurologic

ass, paresthesia insomnia, tinnitus, peripheral neuritis

Hematologic

Dermatologic

rash, pruritus, ecchymosis, petechiae, hyperhidrosis, tetid swea

Genitourinary

Ophipotency, nocturia

conjunctivitis, tearing, blurred vision

Endocrine

of multinodular goiter

Idiosyncrasies

other

ORUG ABUSE AND DEPENDENCE: No evidence of abuse potential has been associated with Lorelco, nor is there evidence of

OVERDOSAGE: There is a single report of a $15-\mathrm{kg}$, three-year-old, male child who ingested $5 \mathrm{~g}$ of probucol. Emesis was induce by ipecac. The child remained well, apart from a bref episode of loose stools and flatulence. No spectic information is avaliab on the treatment of overdosage with Lorelco and no specific antidote is avaliable. Probucol is not dialyzable. Treatment is
symptomatic and supportive. Probucol has shown no identifiable acute toxicity in mice and rats. In these animals, the LDso (oral) is in excess of $5 \mathrm{~g} / \mathrm{kg}$ of body weight.

DOSAGE AND ADMINISTRATION: For adult use only. The recommended and maximal dose is $1000 \mathrm{mg}$ daily given in two divided doses of $500 \mathrm{mg}$ each (two $250 \mathrm{mg}$ tablets or one $500 \mathrm{mg}$ tablet) with the morning and evening meals.

HOW SUPPLIED: $250 \mathrm{mg}$ round, white, fllm-Coated tablets imprinted with either the DOW diamond trademark over the code

$500 \mathrm{mg}$ capsule-shaped, white, film-coated tablets. marked LORELCO 500. Bottles of 100 (NDC 0068-0053-61)

Keep well closed. Store in a dry place. Avoid excessive heat. Dispense in wetl-closed, light-resistant containers with child-resistar

ANIMAL PHARMACOLOGY AND TOXICOLOGY: In rhesus monkeys. administration of probucol in diets containing unusually hig amounts of cholesterol and saturated fat resulted in the death of tour of eight animals after several weeks. Premonitory syncope

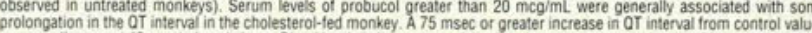

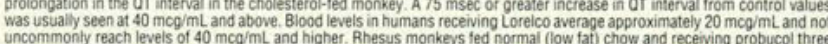
uncommonty reach levels of $40 \mathrm{mcg} / \mathrm{mL}$ and higher. Rhesus monkeys fed normal (low fat) chow and receiving probucol three
to thirty times the human dose equivalent achieved blood levels only one-third those of many human subjects. No adverse eftects to thirty times the human dose equivalent achieved blood levels only one-third those of many human subjects. No adverse effects
were detected in these monkeys over an eight-year period of continuous drug administration. In another study in rithesus monkeys. an atherogenic diet was fed tor two years and daily treatment with probucol, separated in time from the atherogenic meal, was carried out during the second year. Serum probucol levels ranged 20 to $50 \mathrm{mcg} / \mathrm{mL}$ in five of ten monkeys, and less in the
remaining animals. Marked prolangation of the $\mathrm{OT}$ c interval in the ECG or syncopal behavior was never observed over the entive one-year treatment period. Regression of gross artic lesions comparable to that observed in a parallel group of monkeys
receiving cholestyramine was seen in animals receiving probucol. It should be emphasized that both $H D L$-cholesterol and LDL receiving cholestyramine was seen in animals receiving probucol. It should be emphas ized that both $\mathrm{HDL}$-cholesterol and $L D L$.
cholesterol were markedly reduced in this regression study. During the performance of a two-year chronic study involving 32 cholesterol were markedly reduced in this regression study.
probucol-treated dogs (beagles), there were 12 tataities.

Subsequent experiments have indicated that probucol sensitizes the canine myocardium to epinephrine, resulting in ventricular phenomenon of sudden death due to the sensitization of the myocardium to epinephrine. In contrast to findings in the dop In other studies, monkeys were given probucoleither betore and atter, or only after myocardial intarction was induced by coronary
artery ligation. in these studies, there was no difference between probucol- and placebo-treated groups with respect to eithe

Probucol has shown no identifiable toxicity in mice and rats. In these animals, the $L D_{s 0}$ (oral) is in excess of $5 \mathrm{~g} / \mathrm{kg}$ of body weight From studies in rats, dogs, and monkeys, $\pi$ is known that probucol accumulates slowly in adipose tissue. Approximately $90 \%$,
of probucol administered orally is unabsorbed. For that which is absorbed, the biliary tract is the major pathway for clearance from the body and very little is excreted by way of the kidneys.

Myocardial injury was produced in various groups of rats by one of the following procedures: aortic coarctation, coronary ligation,
or cobalt or isoproterenol injection. After probucol administration, no deleterious effects related to treatment occurred as or cobalt or isoproterenol injection. After probucol administration, no deleterious effects related to treatment occurred as
measured by survival and microscopic examination of myocardial damage. Probucol was administered to minipigs beginning ten days before ligation of coronary artery and continued for 60 days atter
surgery. Challenge with epinephrine at the end of 60 days tailed to induce ventricular fibrillation in any of the coronary-ligated. probucol-treated minipigs.

CLINICAL STUDIES: In a multicenter, randomized, double-blind study, the LRC-CPPT, 'hypercholesterolemic patients treated with an oral bile acid sequestrant (cholestyramine) and a cholesterol-lowering diet experienced average total and LLL-cholestero primary end point - combined incidence of definite CHD death and/or detinite nonfatal myocardial infarction - was $7 \%$ in the cholestyramine group and $8.6 \%$ in the placebo group. This was a $19 \%$ reduction in risk (P less than 0.05 , single-tail test) of the The subjects included in the study were middle-aged men ( $35-59$ years old) with serum cholesterol levels at least $265 \mathrm{~m}$ m/dL and hypercholesterolemic population not studied.

The bile acid sequestrant, cholestyramine, was used in the above trial. Caution should be exercised in extrapolating these results to Loreico since it differs trom cholestyramine with regard to its mode of action, spectrum of cholesterol-lowering potency, effect REFERENCES

1. Consensus Development Panel. Lowering blood cholesterol to prevent heart disease.JAMA. 1985; 2532080-2086.
2. Fredrickson DS. Levy Ril, Lees RS. Fat transport in lipoproteins - an integrated approach to mechanisms and disorders. NEng/ 3. The Lipid Research Clinics Program. The Lipid Research Clinics coronary primary prevention trial results: 1 . Reduction in
incidence of coronary heart disease. JAMA. 1984:251:351-364. Product intormation as of June, 1988

J188C

Printed in U.S.A.

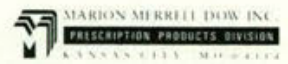



My offerings, in this context, are products of 54 years of experience in medical education and research, 45 of those years in intimate and broad acquaintance with osteopathic physicians as teacher, researcher, curious observer, grateful patient, and persistent asker of questions. The offerings therefore are unavoidably a mixture of documentable "facts" and less objective perceptions, insights, and opinions. I have tried, throughout, to distinguish the objective from the subjective, but given the inevitable coloring of interpretation of objective data by subjective viewpoints, I cannot claim total success. I hope that the reader will assume that there is an experiential, substantive basis for my perceptions.

\section{A heuristic interpretation of osteopathic principles \\ The unity of the person}

Extending unity from body to person has theoretical and clinical implications far more fundamental than they may appear. This is not to deny that the earlier osteopathic emphasis on the unity of the body in clinical practice has been an important contribution to human health. But, it is a remnant of the mechanistic and dualistic Cartesian viewpoint that the body is a machine (and that the physician is a mechanic) and that the mind is quite a separate, and superimposed, entity. The premise underlying research and practice guided by this perspective is that total understanding of the person, as well as the body, can be achieved by study of body parts and processes.

The mechanistic biomedical philosophy that I refer to (and perhaps caricature) has guided medical research for many decades. Its basic premise, whether articulated or not, is that the way to understand anything, including humans, their illnesses, and the origins of their vulnerability, is to take them apart; that is, to reduce them to their components, and to study these and their interactions as minutely as possible. Thus, to understand each human disease, seek the part or the process that has gone wrong, the way it has gone wrong, and what (the cause) has made it go wrong; then find the chemical or physical agent to set the part right and thereby restore the patient to health. The disease is seen as that of the component-the kidneys, the heart, the skin, etc. For obvious reasons, this research paradigm is described as "reductionist."

Having in this critical manner characterized research in the reductionist mode, I hasten to point out that such research is essential to scientific progress and that it has been enormously productive of knowledge about biological structure and process, about the things that go wrong with this or that kind of cell, tissue, or organ, the causative factors and the functional and clinical manifestations of these departures from normal. Many of the medical advances of this century can be ascribed to such analytical research. The growing reservations about the reductionist paradigm are not that it has been unproductive or misguided, but that it is incomplete, most particularly with respect to the human species.

It is incomplete in that it gives little importance or attention to the organismic context. Discounted are the facts that (1) the organism is the environment-the context-in which the parts operate; (2) that human contexts are different from those of the various species from which most of the knowledge about component parts and processes is acquired (that is, that they function in totally different kinds of organisms, living vastly different kinds of lives, in vastly different kinds of environments); (3) that each human provides a context distinct from that of every other human; and (4) that everything about each person, from conception on, subjective as well as objective, enters into determining how well every part functions, for how long, and how it may go wrong.

Reductionism is incomplete in that, in effect, it regards the organism - the person-as merely the sum of body parts. By reducing the organism to its component parts, reductionist research conceptually demolishes the very entity it seeks to understand. It sees too little need to take into account that at each higher level of organizational complexity, properties emerge that cannot be understood or predicted from the properties of the components, and that the components may even be governed by the emergent phenomena. I mean this in the sense that the properties of water cannot be 
predicted from the properties of hydrogen and oxygen, and that once incorporated in water hydrogen and oxygen are constrained by the very molecules that they comprise.

In its drive for universal, all-encompassing laws, reductionism ignores the diversity of expression of these laws from person to person. Valuable as is our knowledge about the heart, it remains an abstraction. There are only hearts, each different from all others according to who the person is and his or her entire history, from conception on. Materialistic in its orientation, reductionism dismisses as irrelevant, the circular interplay between the material (the body) and the impalpable-mind, feeling, belief, past conditioning, etc. Subjective experience is seen as too "soft" for scientific attention. Only that which can be objectively demonstrated, quantified, and replicated is admissible to its realm.

Reductionist biomedical research clings, although somewhat less tenaciously in recent years, to the concept of linear causality - oneway cause-effect relationships-and pursues the quest in medical research and practice for the specific cause and specific cure. In doing so, it overlooks the role of the patient, and of the immense and unique constellation of factors in and around the patient, in both pathogenesis and recovery. Even in infectious disease, in which "specific etiology" seems established, the pioneer in that field, Louis Pasteur, reminded us that the microbe proliferates only when the host has become too hospitable because of preexisting illness. ${ }^{1}$ Finally, reductionist, mechanistic medical research fails to see that when illness occurs, whatever the affected part, it is illness of the person.

It is in this incompleteness that the reductionist paradigm does not meet the requirements of osteopathic research. From the osteopathic viewpoint, nothing can be understood except in relation to something else, and especially to the totality of which it is a part and which it serves. While the knowledge yielded by reductionist research is essential to osteopathic research, the latter requires, in effect, that the knowledge about the component structures and processes be reinserted into the total person whom it serves, where it is subject to the influences of all other parts through the communication systems of the body, and where it is affected by all the factors-physical, chemical, mental, emotional, social, and environmental-that render the human distinct from all other species, and each human different from all other humans. The reinsertion of the parts into the human context accomplishes the needed completion. What is more, when the human is restored to its context, new light is cast on each part: Properties, functions, interactions emerge that are not evident in isolation and out of that context.

This is my personal interpretation and elaboration of "the body is a unit."

\section{The patient's health-maintaining and health-restoring powers}

Osteopathic medical practice is predicated on the patient's inherent "healthcare system." That system comprises all the homeostatic, defensive, and healing functions, including the numerous reflex and humoral self-regulatory mechanisms, the enormously complex immune system and its nervous and humoral control and feedback, the detoxifying mechanisms, the capacities for self-repair and regeneration, and the integrative role of the nervous system, and others well known to biomedical scientists. Included also are the "body's own medicines," more recently called "endocoids," now known to compose a large and diverse pharmacopeia. ${ }^{2}$

The osteopathic physician sees it as his or her major responsibility to evoke and support those mechanisms, to remove all possible impediments to their functions, and, above all, to do them no harm in the course of treatment. The osteopathic physician is aware that it is the patients who get well and not the procedure or the medication that makes them well; that cure comes from within. It is never forgotten that while the physician's care is often crucial to recovery, all treatment ultimately depends on, and would be valueless without, those indwelling mechanisms. They are the ultimate source of health and the means for recovery of health.

This, for me, is the essential meaning of the "body's healing power." 


\section{The musculoskeletal system}

Osteopathic thought and practice seek to integrate the musculoskeletal system into the community of organs and systems and to give it its rightful place in the total organismic scheme.

- More than just the locomotor system, the musculoskeletal system is seen as the instrumentality through which we express every aspect of our humanity and of our individuality. It is the means through which thought, emotion, belief, and moral, ethical, and religious principles find their expression in behavior. It is our means of communication, whether by spoken or written word, signal, gesture, or facial expression. It is the instrument through which intellect and creativity are manifested.

- The most massive of all the body systems, the musculoskeletal system is also metabolically the most demanding on all the other systems to meet its logistic requirements, which vary widely from moment to moment according to what the person is doing, how he or she is responding to the environment and his or her circumstances. As the major "consumer" in the body economy, the musculoskeletal system therefore is the major source of perturbation and of continual and varying challenge to the homeostatic mechanisms of the body.

- Through its rich efferent and afferent connections with the central nervous system and through the large volumes of blood that perfuse it, the musculoskeletal system both influences and reflects what goes on in all other systems and therefore in the person as a whole.

- Much, perhaps most, illness fundamentally may be viewed as discrepancy between musculoskeletal requirements and the meeting of those requirements by other systems, whether the discrepancy is due to (1) inappropriate or excessive behavioral and musculoskeletal demand; (2) musculoskeletal dysfunction; (3) visceral dysfunction, or (4) miscommunication among the systems. The larger the discrepancy, the less able is the musculoskeletal system to serve as the means for body support and motion. Therapeutic rest is automatically imposed.

- Unlike the quadruped, the human musculoskeletal system is peculiarly vulnerable to gravitational and other external forces because of its vertical configuration and its narrow bipedal base. Research (to be cited later) and clinical experience show that resulting dysfunction is communicated to other tissues and organs with deleterious effects, especially to those innervated from related parts of the spinal cord. As has also been shown (and will be cited later), musculoskeletal dysfunction, through the central and autonomic nervous systems, focuses and magnifies the impact of other negative factors in the person's life on neurologically related organs. Somatic dysfunction therefore is a frequent source of impediment to the person's health-maintaining and health-restoring mechanisms.

- Because of its intercommunication with all other systems, thereby both reflecting and influencing what goes on in them, and because of its accessibility, the musculoskeletal system provides a basis both for diagnosis and for the introduction of favorable influences on the other systems and on the person as a whole. Osteopathic manipulative treatment (OMT) of the ill patient is not treatment of the disease but rather treatment of the patient's ability to deal with the disease.

These six features and their clinical and theoretical implications are an interpretation and elaboration of the original principle that "structure determines function" and its more recent version that "structure and function are reciprocally interrelated." Review of the older osteopathic literature indicates that "structure" was not intended as a universal concept but as musculoskeletal structure, as in "structural diagnosis."

\section{The questions}

What kinds of questions are suggested by these expanded versions of osteopathic principles? A few are identified here for consideration by biomedical scientists in osteopathic institutions. Included, also, are some questions that were the products of prior investigations and that have remained unanswered. In research, as in other areas of human endeavor, "It is better," as author James Thurber said in The Fable of Our Times, "to know some of the questions than all of the answers." 


\section{Questions related to the human context}

In what ways have fundamental biological structures, such as heart, lungs, and reticuloendothelial tissues, and processes, such as respiration, metabolism, thermoregulation, and blood circulation, that are shared by all mammals, been adapted to the unique demands of human life? To the upright stance and bipedal locomotion? To the enormous cerebral development and the accompanying new capacities and to the new kinds of demands that they created? To the diverse manmade environments? To the trappings of culture and civilization? Which structures, processes, responses, behavior patterns have remained unmodified and ill-adapted or inappropriate to the requirements of human life? How are all these factors related to human susceptibility to illnesses that are uniquely common in humans, such as the chronic degenerative diseases, and rare in other species (except in domesticated ones)? That is, to what degree is the human capacity for health and human illnesses as much a product of evolution as humans themselves?

\section{Questions related to individual human contexts}

Why do some hearts (stomachs, kidneys, brains, immune systems, etc) go on serving their owners well for $80,90,100$ years or longer, while others succumb much sooner? What resources do the healthy, disease-resistant, long-lived people have that others do not? Aside from heredity, what factors account for their good fortune that can be taught or conveyed to others? Instead of focusing almost exclusively on the causes of this or that disease, should we not seek the "cause" of non-diseaseof health as a phenomenon in itself?

In this connection, the entire field of bodymind interplay, exemplified in the emergence of psychoneuroimmunology as a distinct discipline $^{3}$ is most relevant to osteopathic theory and practice. How are stress, psychic tension, and emotional conflicts somatically expressed, for example, in organ function, in posture, and patterns of muscle tensions? To what extent do the sites of somatic dysfunction determine which parts of the body will be most affected by disturbed mental and emotional states? Conversely, do somatic dysfunctions have mental and emotional repercussions? What kinds of somatic dysfunction, in which parts of the musculoskeletal system?

\section{Questions about the place of the musculoskeletal system in the organismic scheme}

- How have the functions that are shared with other mammals been adapted to or been affected by assumption of the erect posture and by the altered relation to gravitational forces? Circulation to the head? Venous return from the lower parts of the body? Pulmonary ventilation and drainage of bronchial secretions? Lymphatic drainage and immune functions? Postural and righting reflexes? Fetal development and parturition? Others? How are these adaptations to upright posture related to clinical problems common to humans?

- What are the implications of the fact that the autonomic innervation of all of the musculoskeletal system is exclusively sympathetic? That sympathetic preganglionic neurons and motoneurons are located in adjoining columns of the spinal cord, where they are subject to the same or similar presynaptic inputs of somatic, visceral, and cerebral origin?

- Earlier research demonstrated that both motor and sympathetic reflex thresholds are lowered in cord segments related to areas of somatic dysfunction. . $^{411}$

- This facilitation manifests itself in exaggerated and prolonged responses in those segments to incoming impulses from any source, including the brain. What changes in afferent input or in the cord itself (or both) are responsible for lowering the thresholds? One theory implicated muscle spindles and their gammafiber control as a facilitating factor, ${ }^{12}$ another, "garbled" collective input from proprioceptors. ${ }^{13}$ Although compatible with clinical observations, these hypotheses await experimental testing. What maintains those segments in the facilitated state? Does the spinal cord have the capacity for learning and memory, as has been strongly suggested by experimental studies? ${ }^{14}$

- In view of evidence from earlier research 
of facilitation of sympathetic pathways segmentally related to somatic dysfunction, ${ }^{6-10}$ what are the effects of sustained stimulation of the sympathetic innervation of various organs and tissues, including the nervous system itself? Since the exaggerated responses include those to impulses descending from the higher centers, to what extent does facilitation of segmental sympathetic pathways play a role in the visceral and vasomotor manifestations of mental and emotional disturbances?

- Electromyographic recording from the paraspinal musculature in standing subjects has shown that the patterns of sustained and intense muscular activity vary from individual to individual and are constant for each. ${ }^{15,16}$ What factors determine the location of the hyperactive areas? What is their relation to somatic dysfunction and other clinical problems?

- On empirical as well as theoretical grounds, the fascias have long been implicated in somatic dysfunction and are the focus of attention in such manipulative techniques as myofascial release. What functions does fascia have beside its "connective" role? If, indeed, "release" occurs, does this signify that fascia has contractile properties? If the answer is in the affirmative, what are the functional implications?

- Another important area, one that can, according to one's research specialty, be extended to every tissue, organ, and function, is the twoway communication between the musculoskeletal system (and other somatic tissues) on the one hand, and all the remaining systems, including their vasculature, on the other. The mechanisms to be examined are not only those acting via the nervous system, that is, somatoautonomic integration and control, ${ }^{17}$ but also the diverse chemical means of communication and the direct mechanical influence of musculoskeletal activity on viscera and on flow of blood and lymph.

One of the fundamental problems in the context of neural control is the abrupt shift in pathways that occurs in the presence of pathologic alteration. In normal function, efferent neurons are recruited according to what their effectors do, without regard for their location in the neuraxis. When, however, a viscus or so- matic structure innervated from the same segment is injured or becomes dysfunctional (especially if nociceptors are excited), then they are suddenly on a "party line," and their segmental relationship is suddenly conspicuous. ("A segment in view is a segment in trouble."13) Clinically, this phenomenon is widely known in the form of referred pain, in which pain of visceral origin is felt, not in the viscus, but in segmentally related somatic structures (skin, bone, and muscle) in which functional changes, such as muscular contraction, also occur. The phenomenon of newly established "party lines," initiated in both visceral and somatic structures, have also been demonstrated experimentally. $9,10,18-20$

The heart, for example, does not directly participate in any way in the activities of dermatomes, myotomes, or sclerotomes that also receive their innervation from upper thoracic segments of the spinal cord. Similarly, the paraspinal musculature of the upper thoracic segments and the corresponding areas of skin make no contribution to cardiac function. Cardiac systoles and diastoles are totally independent of paraspinal muscle contractions and relaxations. But, given myocardial ischemia or severe intervertebral dysfunction or paraspinal muscle spasm in upper thoracic levels of the spine, then viscus and soma are immediately linked in a self-sustaining circuit of autogenic impulses of which each is both source and victim. What is the mechanism by which that circuit is created? How is it maintained? Can it be prevented? How can it be interrupted noninvasively?

- Although somatovisceral interchange predominantly involves the peripheral sympathetic nervous system, the participation of the parasympathetic division of the autonomic nervous system in the visceral expression of somatic dysfunction remains largely unexplored.

- Under what circumstances and in which musculoskeletal structures does compression of blood and lymphatic vessels occur, and with what effects?

- What are the effects of osteopathic manipulative treatment on aberrant functions and processes, for example, cardiac arrhythmias, uterine inertia, pulmonary ventilation, or various 
aspects of immune, gastrointestinal, or sensory function?

\section{Questions about nonimpulse-based neural functions}

Research has shown that of the many proteins that are synthesized in peripheral neurons and that are axonally transported, only a few selectively cross the junctions with innervated tissues and enter their cells. ${ }^{21-24}$ The transferred proteins, at least in the case of striated muscle, are those not synthesized by muscle cells themselves. The hypothesis was proposed that the transfer of neuronal proteins to innervated tissues is the basic mechanism of long-term, nonimpulse-based trophic functions of nerves.

It was further postulated ${ }^{25}$ that impairment of this function, such as would occur when the nerve is sufficiently compressed to impede axonal transport or when the quality or quantity of neuronal proteins is altered (as in facilitated neuron pools in sustained hyperactivity), could account for some of the remote pathologic effects of somatic dysfunction. It would be of enormous theoretical as well as clinical value to identify the transferred proteins, and to ascertain their loci and functions in the recipient cells.

Do all tissues receive neuronal proteins? Which, if any, do not? How do they differ from those that do? What are the mechanisms of transfer? Would neuronal proteins, known to be essential for regeneration of extremities in certain lizards and amphibia, ${ }^{26}$ have applicability to the human in support of wound healing, for example? That this is a possibility is suggested by the remarkable degree of limb regeneration that was achieved in a mammal, the opossum, by the same technique that succeeded in amphibia, namely hyperinnervation. ${ }^{27}$

Since retrograde axonal transport ( $t o$ the neuron) also occurs, carrying such items as nerve growth factor, chemical feedback from the innervated structure, neurotoxins, and neurotrophic viruses, ${ }^{28}$ could this mechanism be used to administer therapeutic agents to selected neuron pools that have been injured, infected, or affected by toxins?

\section{Questions about cranial mechanisms}

Another rich area awaiting further exploration at the basic science level is that related to cranial biomechanics. What, for example, is the origin of palpable and recordable ${ }^{29}$ movements of the cranial bones (apparently around the sutures that join them? ${ }^{30}$ In humans, these movements are usually maintained at quite regular rates of about 8 to 12 per minute, and are independent of the respiratory rate and arterial pulse rate. They seem to be synchronous, however, with the plethysmographic (volumefluctuation) rhythm in peripheral tissues. Are these cranial movements related in any way to fluctuations in volume or pressure of the cerebrospinal fluid, or rhythmic contractions and relaxations of large veins? Is impaired cranial motion or rhythm related to malfunction elsewhere in the body?

\section{Questions about endocoids}

A great contribution to biomedical science that would have broad applicability would be the design of methods and measures by which to evoke, as necessary, the "body's own medicines." These include the numerous neuropeptides, the prostaglandins, various hormones, interleukins, interferons, and others yet to be discovered.

\section{Other questions}

These are but a few of the questions related to osteopathic theory and practice that, it seems to me, offer research opportunities for anatomists, physiologists, biochemists, neuroscientists, pharmacologists, immunologists, psychologists, and others. Bioscientists need hardly be reminded that in addition to the preceding questions much remains to be learned about all of the inherent self-regulatory, homeostatic, defensive, healing, recuperative, and regenerative mechanisms that are so important to the maintenance and restoration of health and factors that affect them favorably as well as unfavorably.

\section{Clinical research}

This section is limited to research the purpose of which is to assess the effectiveness of osteopathic medical care. Having had little experi- 
ence in this area, I can claim no personal authority, and must rely totally on the contributions of those who have demonstrated competence in such research. I have learned also from the mistakes of others who have sought to use experimental designs inappropriate to osteopathic medical practice. It is my purpose in this section only to emphasize that in designing and undertaking such studies, investigators must keep in mind that osteopathic medical practice and methodology, a central component of which is OMT, are derivatives of osteopathic philosophy; and, therefore, that assessment of effectiveness must be tested in that context and with criteria consonant with that context and no other. I also offer some research designs that appear to be eminently suitable or adaptable to this purpose.

Designs are required that assess the effect of treatment not merely on the presenting complaint, dysfunction, or disease, but the impact of treatment on the total person and the person's ability to carry on, with adequate reserve, the functions that are important to him or her. The designs should also make possible comparisons with other systems of care. Other qualifications will become clear as we examine the ways in which conventional clinical trials are usually inappropriate to assessment of osteopathic practice and especially OMT.

Most clinical trials are designed to assess the effects of a given medication, physical agent, or therapy on a given clinical problem. With few exceptions, the therapy is so uniform or standardized that its effect is hardly, if at all, influenced by the person who prescribes or administers it. It matters a great deal, however, who administers OMT (as well as who receives it), by his or her training, prior years of manipulative experience, choice of diagnostic cues, technique preferences, and so forth. (My own experience over many years as recipient of osteopathic medical care is that "style" and effectiveness are as diverse and idiosyncratic as the personalities of the physicians.)

This variability is further compounded by variation in response, not only from patient to patient and from visit to visit, but also from moment to moment as the (skilled and discern- ing) osteopathic physician assesses tissue and patient response to each maneuver, and then selects and applies succeeding ones accordingly. In effect, physician and patient are linked in a cybernetic loop - a "wordless dialogue"-in which each responds to the other's changing input. ${ }^{31}$

Conventional clinical trials require large randomized populations that are divided into experimental and control groups to compensate statistically for unavoidable sources of ambiguity, such as the variations in the "effects" of the therapy. (In the osteopathic perspective, the variations are in the patients' response to therapy.)

The second source of error or ambiguity to be compensated for is the "spontaneous" recovery, remission, or improvement that would occur in unknown percentages of patients in the absence of treatment. Compensation is made by administering a placebo or sham treatment to the members of the control group, who are matched (age, sex, clinical status, etc) as closely as possible to the experimental group, who receive the real treatment. Both patients and evaluating physicians are "blinded," that is, not permitted to know who receives the placebo and who, the treatment under test.

The placebo is "medication" or "therapy" that is inert and that looks and tastes like the "real" thing. A favorable response to such treatment is regarded as the "placebo effect," which must be taken into statistical consideration in assessment of efficacy of the treatment being tested.

The osteopathic physician, however, is aware that spontaneous recovery or the placebo effect is a response-an active response of the patient's recuperative mechanisms and a demonstration of their potency. The response is evoked, not by the sugar pill or nontreatment, but by such factors as confidence in the treatment, positive beliefs, expectations, and attitudes with respect to the illness and its outcome or even by desperation - "this has got to work!"

The osteopathic physician knows that whatever the treatment and however great its role in favorable clinical outcome, that role is made possible only through the patient's own heal- 
ing resources. Hence, the osteopathic physician not only does not wish to suppress or "rule out" their role, but he or she also relies on those resources, and seeks in every way to evoke, encourage, disencumber, and support those mechanisms and to call on the body's own medicines. The physician does this not only by the treatment, but also by touch, word of mouth, tone of voice, body language, and confidence expressed in the patient's ability to get well. Therefore, that which is regarded as nuisance and source of error from one perspective is essence and source of clinical results from the osteopathic perspective.

It is essential, therefore, that assessments of effectiveness of OMT be of OMT as it is practiced, as an integral part of the total interaction between physician and patient, and not as an isolated, contrived, and standardized procedure which, though nicely amenable to statistical analysis, is totally unrelated to clinical reality. "As it is practiced" means that experimental designs must be such as to accept as given (1) that OMT, unlike medications, and their dosages, cannot be made standard and uniform; (2) that the placebo response is an integral, inseparable part of the patient's total response to osteopathic medical care. Also, criteria of change in clinical status must be chosen that are consonant with osteopathic perspectives and practice.

Given these constraints, what kinds of clinical assessment designs are already available or can be devised that are appropriate to osteopathic medical practice?

Almost ideally suited to this purpose is the so-called Medical Outcomes Study (MOS). Highly refined and rigorous versions of the MOS have been described in a recent series of papers. ${ }^{32-38}$ The criteria of clinical outcome employed in these studies were in five categories, each of which includes a number of quantitatively assessable items, which, despite the subjective nature of some of them, are collectively amenable to a high degree of reliability of statistical analysis:

- physical functioning (ability to perform a variety of physical activities);

- role (ability to carry out daily activities such as housework, vocational work;
- socialization (ability to conduct social and group activities, visiting with friends);

- mental health (general mood or affect, sense of well-being);

- health perception (self-rating of current health in general); and

- bodily pain.

Osteopathic clinical researchers would find study of these papers and of others cited therein highly rewarding, as they would the book Measuring Health. ${ }^{39}$ The basic design of these studies is readily adaptable to the assessment of the effectiveness of osteopathic medical care that includes OMT and to its comparison with other medical systems.

In view of the two-way, dialoguelike relation between osteopathic physician and patient and the patient's involvement in OMT, consideration should also be given to adopting, or adapting as necessary, designs successfully used in the behavioral and social sciences and in psychotherapy. Of special interest are the intrasubject (so-called $\mathrm{N}$ of 1 ) and intersubject designs involving individuals and small groups. ${ }^{40-49}$

Finally, another approach would be to take advantage of ready-made patient populations, such as in health maintenance organizations and in industrial plants, in which some people are under osteopathic medical care, the others under allopathic medical care. Longitudinal studies on comparative outcomes, such as incidence of minor illnesses and disabilities (headaches, backaches, colds, dysmenorrhea) and of various diseases and degrees of recovery, length of convalescence, absenteeism, and so forth, in the two populations would be of enormous value.

\section{Summary}

The purposes of this article are twofold: (1) To assist scientists on the faculties of colleges of osteopathic medicine in the design of research projects relevant to osteopathic medical theory and practice; and (2) to assist clinical investigators in the development of research protocols that are best suited to the assessment of clinical outcomes of osteopathic medical practice. Toward this end, the central osteopathic medical principles are heuristically inter-

(continued on page 170) 


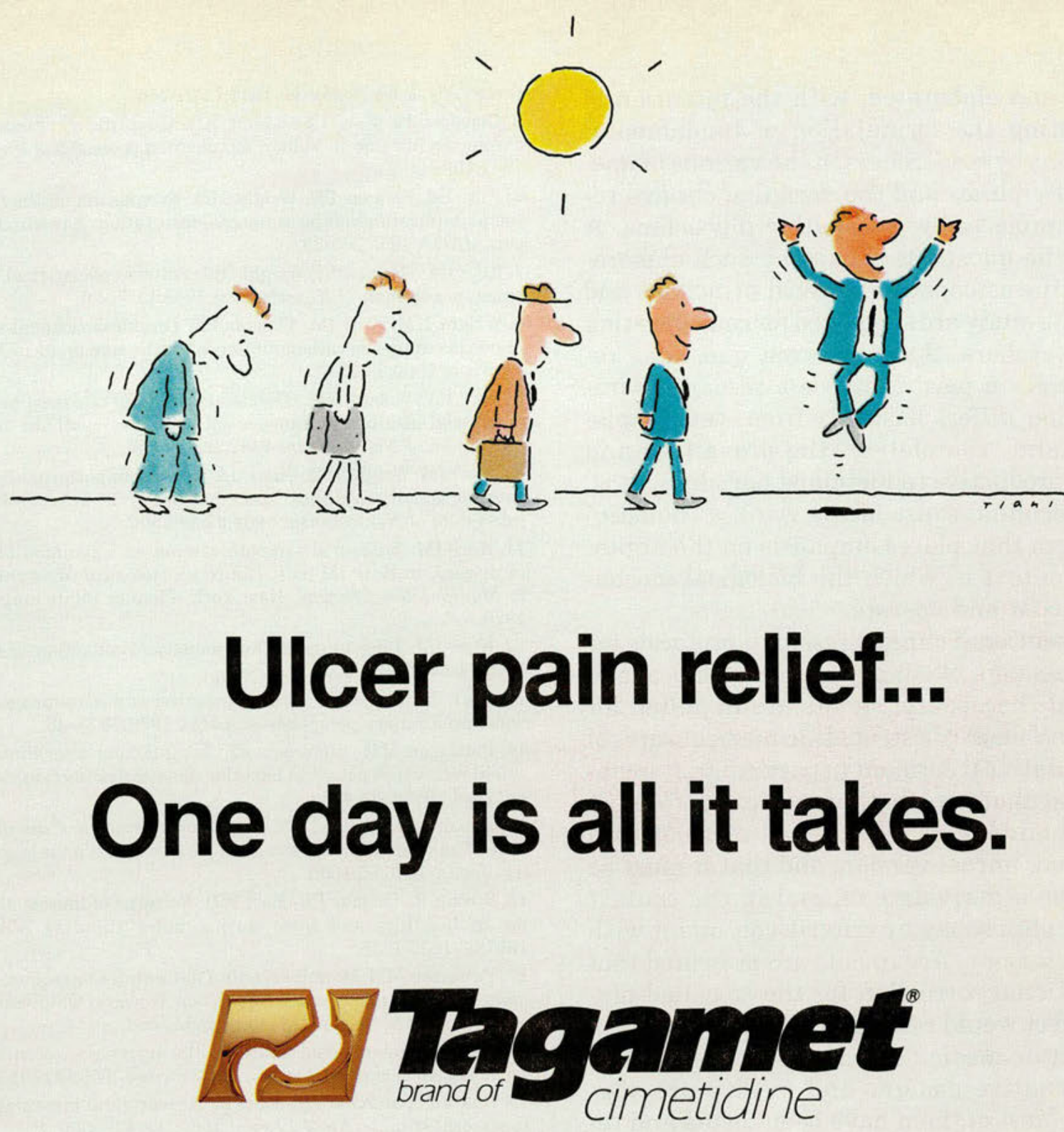

\section{TAGAMET' /brand of cimetidine/}

See complete prescribing information In SKEF LAB CQ. Iiterature or PDR. The following is a brief summary.

Contralndications: 'Tagamet' is contraindicated for patients known to have hypersensitivity to the product.

Precautlons: Rare instances of cardiac arrhythmias and hypotension have been reported following the rapid administration of 'Taga

mptomaticresponseco 'Tagamer' therapy does not preclude the presence symptomatic response to Tagamet therapy does not preclude the presence of a gastric malignancy. There have been rare reports of transient

Reversibie confusional states have been observed on occasion, predominantly in severely ill patients.

Tagamet' has been reported to reduce the hepatic metabolism of warfarin type anticoagulants, phenytoin, propranolol, chlordiazepoxide, diazepam certain tricyclic antidepressants, lidocaine, theophylline and metronidazole Clinically significant effects have been reported with the warfarin ant caagulants; therefore, close monitoring of prothrombintime is recommended, and adjustment or the anticoaguiant oose may be necessary when Tagamer theophylline has also been reported to produce adverse clinical effects.

However, a crossover study in healthy subjects receiving either 'Tagamet' 300 $\mathrm{mg}$ q.i.d. or $800 \mathrm{mg} \mathrm{h}$. concomitantly with a $300 \mathrm{mg}$ bi.d. dosage of theophyline /Theo-Durt, Key Pharmaceuticals, inc, demonstrated iess altera tion in steady-state theophylime peak serum ieveis with the aco mg h. regimen, particularly in subjects aged 44 years and older. Data beyond ten monitored appropriately, regardless of concomitant drug therapy!

In a 24 month toxicity study in rats, at dose levels approximately 8 to 48 times the recommended human dose, benign Leydig ceil tumors were seen. Thes were common in both the treated and control groups, and the inciden

A weak antiandrogenic effect has been demonstrated in animals. In human studies, Tagamet' has been shown to have no effect on spermatogenesis, sperm count, motility, morphology or in vitro fertilizing capacity. Pregnancy Category B: Reproduction studies have been performed in rats.
rabbits and mice at doses up to 40 times the normal human dose and hav revealed no evidence of imoaired fertility or harm to the fetus due to Tagamet. tus due to Tagamet. women. Because animal reproductive studies are not always predictive of human response, this drug should be used during pregnancy onlyif clearly needed.

Lack of experience to date precludes recommending 'Tagamet' for use in children under 16 unless anticipated benefits outweigh potential risks; children under cimetidine is secreted in human milk.

Adverse Reactions: Diarrhea, dizziness, somnolence, headache Reversible confusional states (eg. mental confusion, agitation, psychosis, depression anxiety, hallucinations, disorientation,, predominantly in severely lil patients have been reported. Reversible impotence in patients with pathologica hypersecretory disorders receiving 'Tagamet, particularly in high doses for scale surveillancestudies atregular doses has not exceeded that commonily reported in the general population. Gynecomastia has been reported in pa tients treated for ane month or ionger. Decreased white blood cell counts in Tagamet'-treated patients (approximately I per 100,000 patients), including agranulocytosis (approximately 3 per million patients), have been reported including a few reports of recurrence on rechallenge. Most of these reports were in patients who had serious concomitant illnesses and received drugs andior treatment known to produce neutropenia. Thrombocytopenia lapproximately 3 per million patients) and, very rarely, cases of aplastic anemia have also been reported. Increased serum transaminase has been reported. Reversible adverse hepatic eflects, cholestabic or mixed cholestatichepatoceliular in nature, have beenrepontedrarely. Because or the predominance of cholestabic features, severe parenchymar injury is considered highiy checiving Tagamer' has been reported increased plasma creatinine has been recering Tagamer' has beenreponted. Ir reported. Rare cases or fever, interstinin nephohlaxis an thypersensitivity vascultitis, have been reported. Rare cases of bradycardia, tachycardia and AV heart block have been reported with $H_{r}$-receptor antagonists. Reversible arthralgia, myalgia and exacerbation of joint symptoms in patients with pre existing arthritis have been reported rarely. Rare cases of polymyositis have been reported, but no causal relationship has been established. Mild rash and, very rarely, cases of severe generalized skin reactions/e.g. Stevens.Johnson syndrome, epidermal necrolysis, erythema muitiforme, exfoliative dermatitis and generalized exfoliative erythrodermal have been reported with $H_{y}$-receptor antagonists. Reversible alopecia has been reported very rarely.
How Supplled: Tablets: $200 \mathrm{mg}$ tablets in botties of 100:300 mg tablets in use 30 and Single Unit Packages of 100 (intended for institutional use onlyl. Uquid: $300 \mathrm{mg} / 5 \mathrm{~mL}$, in 8 fl oz $(237 \mathrm{~mL}$ amber glass bottles and in single dose Uquid: $300 \mathrm{mg} / 5 \mathrm{~mL}$, in 8 fl oz (237 mL/ amber glass bottles and in single dose
units $1300 \mathrm{mg} / 5 \mathrm{~mL}$, in packages of 10 (intended for institutional use only). In/ection:

Vection: $300 \mathrm{mg} / 2 \mathrm{~mL}$ in single-dose vials, in packages of 10 and 30 , and in $8 \mathrm{~mL}$ multiple-dose vials, in packages of 10 and 25.

Prefliled Syringess $300 \mathrm{mg} / 2 \mathrm{~mL}$ in single-dose prefilled disposable syringes.

SIngle-Dose Prem/xed Plastic Contalners: $300 \mathrm{mg}$ in $50 \mathrm{~mL}$ of $0.9 \%$ Sodium Chloride in single-dose plastic containers, in packages of 4 units. No preservative has been added.

Exposure of the premixed product to excessive heat should be avoided. It is recommended the product be stored at controlied room temperature. Brief exposure up to $40^{\circ} \mathrm{C}$ does not adversely affect the premixed product.

ADD-Vantage ${ }^{*}$ Vlals: $300 \mathrm{mg} / 2 \mathrm{~mL}$ in single-dose $A D D$.Vantage ${ }^{*}$ Vials, in packages of 25.

Tagamet' (brand of cimetidine hydrochloride) Injection premixed in single. dore Corporation, Deerfield, IL 60015.

BRS-TG:LBOB

Date of issuance Oct. 1989 
preted and elaborated, with the intention of facilitating the formulation of fundamental questions by researchers in the various biomedical disciplines and the design of clinical research projects by osteopathic physicians. A few of the questions evoked by such elaboration of the osteopathic medical principles and awaiting study are suggested for consideration by researchers. Such research questions require and, in part, compose a research paradigm that differs basically from, yet complements and "completes," the prevailing and highly productive reductionist paradigm. It is, in the original sense of the word, a "holistic" paradigm that places emphasis on the organismic context in which the biological mechanisms exist and operate.

Conventional clinical research protocols for the assessment of efficacy of most chemical and physical therapeutic agents are ill-suited for the assessment of osteopathic medical care, of manipulative treatment in particular. It is emphasized that osteopathic medical care must be evaluated as it is practiced and not as a contrived, unreal version; and that it must be tested as a derivative of, and in the context of, that philosophy by criteria consonant with that philosophy. Arguments are presented that conventional correction for the so-called placebo effect would render invalid the testing of osteopathic medicine as it is practiced.

Alternative designs and models are suggested. Most of them have been tested and reported in the clinical literature; others await careful trial and development under osteopathic auspices.

I am deeply grateful to Albert F. Kelso, PhD, Chicago College of Osteopathic Medicine, for bringing the development of the Medical Outcomes Study to my attention and for his valuable criticisms of a previous draft of this paper.

1. Dubose R: Mirage of Health. Utopias, Progress and Biological Change. New York, Harper \& Brothers, 1950 p 79.

2. Harbans L, LaBella F, Lane J (eds): Endocoids. New York, Alan R Liss Inc, 1985.

3. Locke S, Adler R, Besedovsky H, et al (eds): Foundations of Psychoneuroimmunology. Hawthorne, NY, Aldin Publishing Co, 1985.

4. Denslow JS: An analysis of the variability of spinal reflex thresholds. $J$ Neurophysiol 1944;7:207-216.

5. Denslow JS, Korr IM, Krems AD: Quantitative studies of chronic facilitation in human motoneuron pools. Am J Physiol 1947;105:229-238.

6. Korr IM, Thomas PE, Wright HM: Symposium on the functional implications of the segmental facilitation: A research report. JAOA 1955;265-282.

7. Korr IM, Thomas PE, Wright HM: Patterns of electrical skin resistance in man. $J$ Neurotransm 1958;17:77-96.

8. Wright HM, Korr IM, Thomas PE: Local and regional variations in cutaneous vasomotor tone of the human trunk. J Neurotransm 1960;22:33-52.

9. Korr IM, Wright HM, Thomas PE: Effects of experimental myofascial insults on cutaneous patterns of sympathetic activity in man. $J$ Neurotransm $1962 ; 23: 329-355$.

10. Korr IM, Wright HM, Chace JA: Cutaneous patterns of sympathetic activity in clinical abnormalities of the musculoskeletal system. $J$ Neurotransm 1964;25:589-606.

11. Korr IM: Sustained sympathicatonia as a common factor in disease, in Korr IM (ed): The Neurobiological Mechanisms in Manipulative Therapy. New York, Plenum Publishing Co, 1978.

12. Korr IM: Proprioceptors and somatic dysfunction. JAOA 1975;74:638-650.

13. Korr IM: The spinal cord as organizer of disease processes: Some preliminary perspectives. JAOA 1976;76:35-45.

14. Patterson MM, Steinmetz JE: Long-lasting alterations of spinal reflexes: A potential basis for somatic dysfunction. Manual Med 1986;2:38-42.

15. Robbins RL, Wright HM: Preliminary studies of the influence of an acute postural stress on paravertebral muscle activity. JAOA 1966;65:1000.

16. Strong R, Thomas PE, Earl WD: Patterns of muscle activity in leg, hip, and torso during quiet standing. JAOA 1967;66:1035-1038.

17. Patterson MM, Howell JN (ed): The Central Connection: Somatovisceral/Viscerosomatic Interaction. Newark, Ohio, American Academy of Osteopathy, to be published.

18. Hix EL: Uretero-renal reflex facilitating renal vasoconstrictor responses to emotional stress. Am J Physiol 1958;192:191-197.

19. Eble JN: Patterns of response of paravertebral musculature to visceral stimuli. Am J Physiol 1960;198:429-433.

20. Eble JN: Reflex relationship of paravertebral musculature. Am J Physiol 1961;200:939-943.

21. Korr IM, Wilkinson PN, Chornock FW: Axonal delivery of neuronal components to muscle cells. Science 1967;155:342345.

22. Korr IM, Appeltauer GSL: The time-course of axonal transport of neuronal proteins to muscle. Exp Neurol 1974;43:452463.

23. Appeltauer GSL, Korr IM: Axonal delivery of soluble, insoluble and electrophoretic fractions of neuronal protein to muscle. Exp Neurol 1975;46:132-146.

24. Appeltauer GSL, Korr IM: Further electrophoretic studies on proteins of neuronal origin in muscle. Exp Neurol 1977;57:713724 .

25. Korr IM: The spinal cord as organizer of disease processes: IV. Axonal transport and neurotrophic function in relation to somatic dysfunction. JAOA 1981;80:451-459.

26. Singer M: Neurotrophic control of limb regeneration in the newt. Ann NY Acad 1974;228:308-322.

27. Mizelle M: Limb regeneration: Induction in the newborn opossum. Science 1968;161:283-286.

28. Thoenen H, Schwab M, Barde YA: Transfer of information 
from effector organs to innervating neurons by retrograde axonal transport of macromolecules, in Korr IM (ed): The Neurobiologic Mechanisms in Manipulative Therapy. New York, Plenum Publishing Co, 1978, p 311-332.

29. Frymann VM: A study of the rhythmic motions of the living cranium. JAOA 1971:70:928-945.

30. Retzlaff EW, Michael DK, Roppel RM: Cranial bone mobility. JAOA 1975;74:869-873.

31. Korr IM:Somatic dysfunction, osteopathic manipulative treatment and the nervous system: A few facts, some theories, many questions. JAOA 1986;86:109-114.

32. Greenfield S: The state of outcome research: Are we on target? N Engl J Med 1989;320:1142-1143.

33. Stewart Al, Greenfield S, Hays RD, et al: Functional status and well-being of patients with chronic conditions. Results from the Medical Outcomes Study. JAMA 1989;262:907-913.

34. Wells KB, Stewart A, Hays RD, et al: The functioning and well-being of depressed patients. Results from the Medical Outcomes Study JAMA 1989;262:914-919.

35. Tarlov AR, Ware JE Jr, Greenfield S, et al: The Medical Outcomes Study. An application of methods for monitoring the results of medical care. JAMA 1989;262:925-930.

36. Riesenberg D, Glass RM: The Medical Outcomes Study. JAMA 1989;262:943.

37. Applegate MD, Blass JP, Williams TF: Instruments for the functional assessment of older patients. $N$ Engl $J$ Med 1990;322:1207-1214.

38. Catford JC: Positive health indicators-towards a new information base for health promotion. Community Med 1983;5:122-132.

39. McDowell I, Newell C: Measuring Health: A Guide to Rat- ing Scales and Questionnaires. New York, Oxford University Press, 1987.

40. Barlow DH, Hersen M: Single Case Experimental Designs: Strategies for Studying Behavior Change, ed 2. New York, Pergamon Press, 1984.

41. Barlow DH, Hayes SC, Nelson RO: The Scientist Practitioner: Research and Accountability in Clinical and Educational Settings. New York, Pergamon Press 1984.

42. Crayton JW, Stone T, Stein G: Epilepsy precipitated by food sensitivity: Report of a case with double-blind placebo-controlled assessment. Clin Electroencephalogr 1981;12:192-198.

43. Davis DR: Single case research ( $\mathrm{N}$ of 1 studies). J Appl Nutr 1987;39:1-5.

44. Guyatt G, Sackett D, Chong J, et al: Determining optimal therapy - randomized trials in individual patients. $N$ Engl $J$ Med 1986;314:889-892.

45. Kazdin AE: Single-Case Research Designs: Methods for Clinical and Applied Settings. New York, Oxford University Press, 1982.

46. Keating JC, Seville J, Meeker WC, et al: Intrasubject experimental designs in osteopathic medicine: Applications in clinical practice. JAOA 1985;85:192-203. (Excellent list of references)

47. Kelso AF: Planning, developing and conducting osteopathic clinical research. JAOA 1981;80:744-749.

48. Kratochwill TR: Single Subject Research: Strategies for Evaluating Change. New York, Academic Press, 1978.

49. McLeod RS, Taylor DW, Cohen Z, et al: Single-patient randomised clinical trial use in determining optimum treatment for patient with inflammation of Kock ileostomy reservoir.Lancet 1986;1:726-728. 


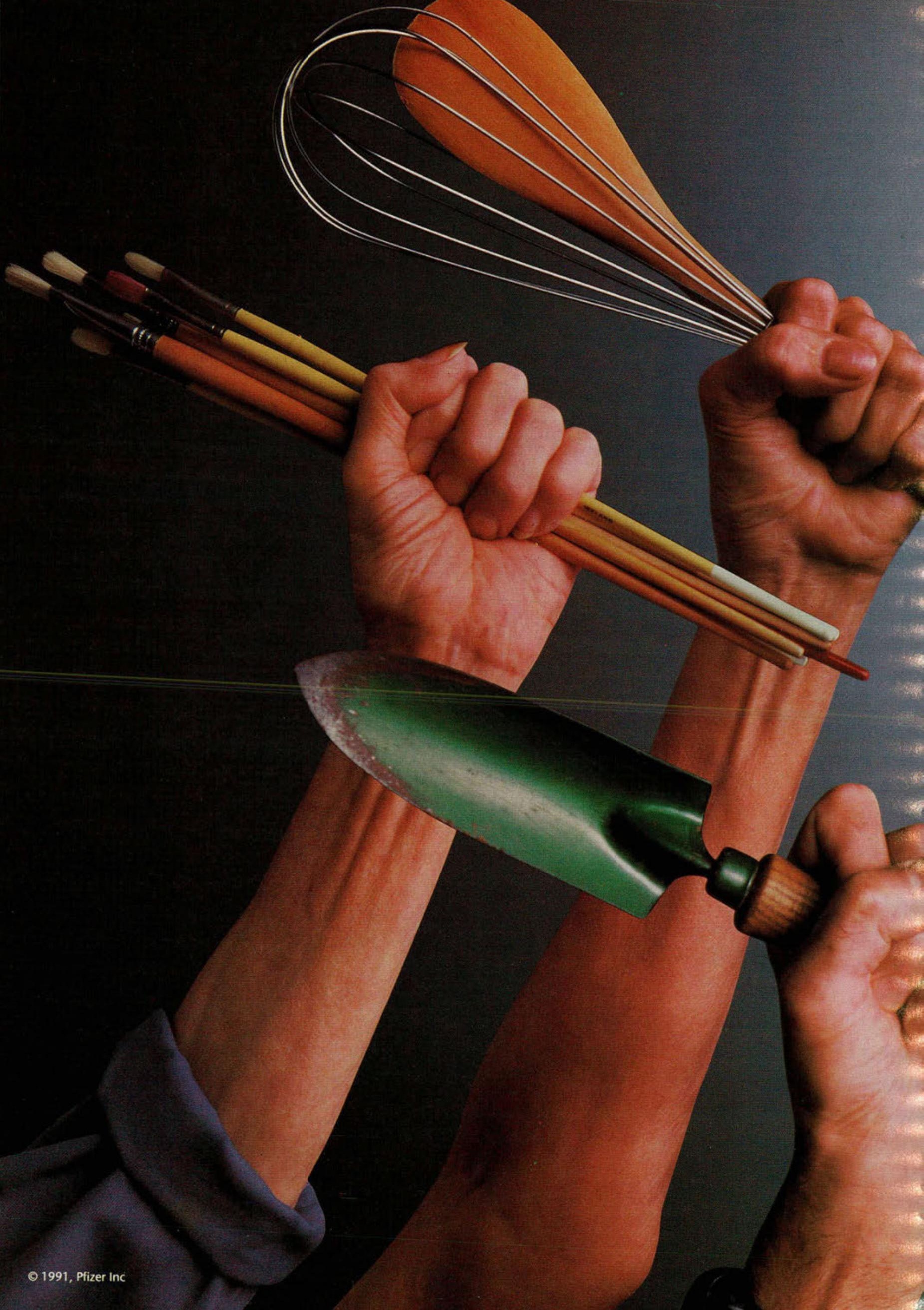




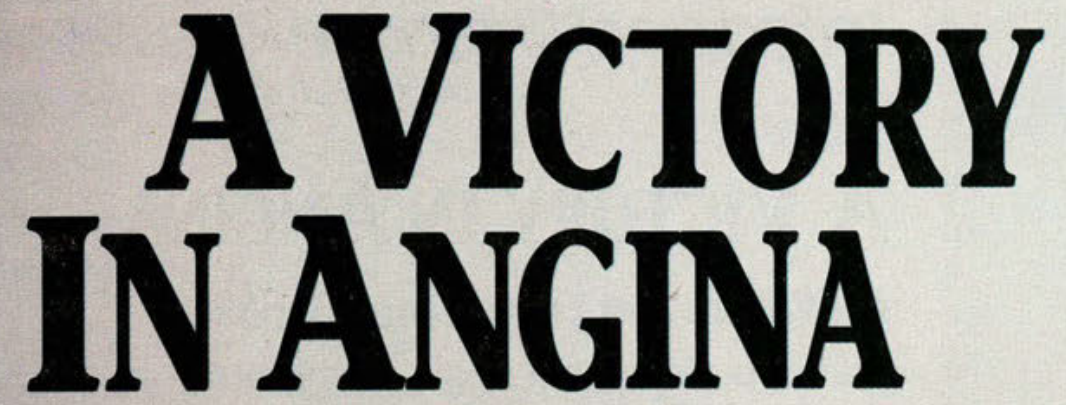

Your patients are vulnerable to anginal attacks every hour of the day and night.

PROCARDIA XL, taken once a day, offers the assurance of predictable 24-hour plasma levels ${ }^{1}$ and the confidence of full 24-hour control ${ }^{2}$ .... victory in angina.

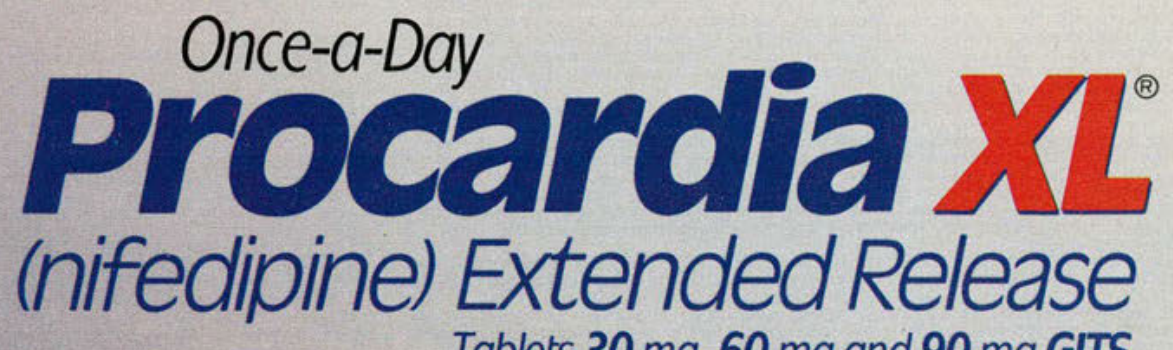
Tablets $30 \mathrm{mg}, 60 \mathrm{mg}$ and $90 \mathrm{mg}$ GITS

\section{CONFIDENT 24-HOUR CONIROL WITH ONCE-DAIIY DOSING}




\section{CONFIDENT 24-HOUR CONIROL WITH ONCE-DAIIY DOSING}

\section{Once-a-Day

\section{A VictoRY IN ANGINA}

\section{Confidence and Convenience Combined}

- Start patients on a single 30-mg or 60-mg PROCARDIA XL Extended Release Tablet, swallowed whole, once a day

- In patients with angina, doses above $90 \mathrm{mg}$ should be used with caution and only when clinically warranted

- Side effects include peripheral edema, which is not associated with fluid retention, and headache

\section{PROCARDIA XL Also Provides Confident 24-Hour Control of Elevated Blood Pressure ${ }^{3}$}

- In patients with hypertension, doses above $120 \mathrm{mg}$ are not recommended

References:

1. Chung M, Reitberg DP, Gaffney M, Singleton W. Clinical pharmacokinetics of nifedipine gastrointestinal therapeutic system: a controlled-release formulation of nifedipine. Am / Med.

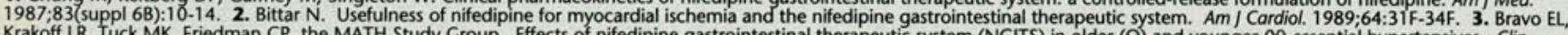
Krakoff LR, Tuck MK, Friedman CP, the MATH Study Group. Effects of nifedipine gastrointestinal therapeutic system (NGITS) in older (O) and younger (V) essential hypertensives. Clin
Pharmacol Ther. 1990;47:199. Abstract.

Briet Summary

For Oral Use

CONTRAINDICATIONS: Known hypersensitivity reaction to nifedipine:

Coumarin Anticoagulants: There have been rare reports of increased prothrombin time in patients taking coumarin anticoagu-

WankinoS: Excessive Hypotension: Athough in most angina patients the hypotensive effect of niffedipine is modest and we: tolerated, occasional patients have had excessive and pooriy tolerated thypotension. These responses have usually occurre beta Dlockers.

Cimetidine: A study in six healthy volunteers has shown a significant increase in peak niffedipine plasma levels (80\%) and areaunder-the-curve (74\%), after a one week course of cimetidine at $1000 \mathrm{mg}$ per day and nifedipine at $40 \mathrm{mg}$, per day. Ranitidine procytochrome P-450, the enzicyme system probably responsible for the first-pass metabolism infibtion of cimetidine on hepatic intiated in a patient currently receiving cmetidine, cautious titration is advised.

Severe hypotension and/or increased fluid volume requirements have been reported in patients receiving nifedipine together with high dose fentanyl appears to be due to the combination of nifedipine and a beta blocker, but the possibility. that in may occir with nifedipine alone, with low doses of tentanyl, in other surgical procedures, or with other narcotic analogesics cannot be ruled out. In nifedipine-treated patients where surgery using high dose fentanyl anesthesia is contemplated, the physician should be
aware of these potential problems and if the patients condition permits, sufficient time (at least 36 hours) should be allowed for

nifedipine to be washed out of the body prior to surgery. Increased Angina and/or Myocardial Infaretion: Rarely, patients, particularly those who have severe obstructive coronary arter disease, have developed well documented increased freguency, duration and/or severity of angina or acute myocardial infarction Beta Blocker Withdrawa: It is important to taper beta blockers if possible, rather than stopping them abruptly betore beginning related to increased sensitivity to catecholamines. Initiation of nifedipine treatment will not prevent this occurrence and on occ:

sion has been reported to increase it. pine. Patients with tight aortic stenosis may be at greater nisk for such an event, as the unloading effect of
expected to be of less benefit to those patients, owing to their fixed impedance to flow across the aortic valve.

PRECAUTIONS: General- Hypotension: Because nifedipine decreases peripheral vascular resistance, careful monitoring of mended for patients a liready taking medications that are known to lower blood pressure. (See WARNINGS.)

Peripheral Edema: Mild to moderate peripheral edema occurs in a dose dependent manner with an incidence ranging from approximately $10 \%$ to about $30 \%$ at the highest dose studied $(180 \mathrm{mg})$. It is a localized phenomenon thought to be associated etention. With patients whose angina or hypertension is complicated by congestive heart fallure, care should be taken to differOther. As with any other non-deformable material, casution should be used when administering PROCARDIA XL in patients with preexisting severe gastrointestinal narrowing (pathologic or iatrogenic). There have been rare reports of obstructive symptoms in Laboratory Tests: Rare, usually transient, but occasionally significant elevations of enzymes such as alkaline phosphatase, CPK
$L \mathrm{DH}$, SGO, and SGP have been noted. The relationship to nitedipine therapy is uncertain in most cases, but probable in some. 作 was an isolated finding not assocated with clinical syymptoms and it rarely resulted in vatues which fell outside the normal range. Rare instances of allergic hepatitis have been reported. In controlled studies, PROCARDIA XL did not adversely affect serum unic acid, glucose, or cholesterol. Serum potassium was unchanged in patients receiving PROC
tant diuretic therapy, and slightly decreased in patients receiving concomitant diuretics

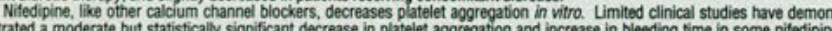
strated a moderate but statistically significant decrease in platelet aggregation and increase in bleeding time in some nifedipine for these findings has been demonstrated.
Positive direct Coombs test withwithout hemolytic anemia has been reported but a causal relationship between niffedipine dministration and positivity of this laboratory test, including hemolysis, could not be determined.

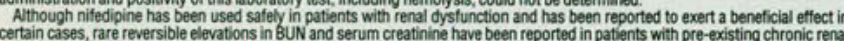
insutficiency. The relationship to nifedipine therapy is uncertain in most cases bet probable in some.
Drug Interactions- - Beta-adrenergic blocking agents. (See WARNINGS) Experience in over 1400 patients with Procardia capsules in a noncomparative clinical trial has shown that concomitant administration of nifedipine and beta-blocking agents is usual. congestive heart tailure, severe hypotension, or exacerbation of angina.
Long Acting Nitrates: Nifedipine may be safely co-administered with nitrates, but there have been no controlled studies to evalDigitalis: Administration of nifedipine with digoxin increased digoxin levels in nine of twelve normal volunteers. The average
increase was $45 \%$. Another investigator found no increase in digoxin levels in thirteen patients with coronarn artery disease. In an increase was $45 \%$. Another investigator found no increase in digoxin levels in thirteen patients with coronary artery disease. In an
uncontrolled study of over two hundred patients with congestive heart failure during which dipoxin blood levels were not mea-
sured, digtais toxicity was not observed. Since there have been isolated reports of patients with elevated digoxin levels it it is recCarcinogenesis, Mutagenesis, impairment of Fertlity. Nitedipine was administered orally to rats, for two years and was not the maximum recommended human dose. In vivo mutagenicity studies were negative. Pregnancy. Pregnancy Category C. Nifedipine has been shown to be teratogenic in rats when given in doses 30 times the maximum
recommended human dose. Nifedipine was embryotoxic (increased fetal resorptions, decreased fetal weight, increased stunted forms, increased fetal deaths, decreased neonatal survival) in rats, mice, and rabbits at doses of from 3 to 10 imes the maximum recommended human dose. In pregnant monkeys, doses 233 and twice the maximumm recommended human dose resulted in sma pregnancy. There are no adequate and well controlled studies in pregnant women. PROCARDIA XL (nifedipine) Exiended Release Tablets should be used during pregnancy only if the potential benefit justifies the potential risk to the fetus.

hypertension and angina were included in the evaluation of adverse experiences. Al side effects reported during PROCARDIAXL reported with PROCARDIA XL. was edema which was dose related and ranoed in frequenodication. The most common side efftect at the highest dose studied $(180 \mathrm{mg})$. Other common adverse experiences reported in placebo-controlled trials include: headache (15.8\%, compared to $9.8 \%$ placebo incidence), fatigue (5.9\%, compared to $4.1 \%$ placebo incidence), diziness (4.1\%, compared placebo incidence). Of these, onty ederna and headache were more common in PROCAR, a IA XL patients than placebo patients. The following adverse reactions occurred with an incidence of less than $3.0 \%$. With the exception of leg cramps, the incidence
of these side effects was similar to that of placebo alone: body as a whole'systemic : asthenia, flushing, pain, cardiovascular: palpitations, central nervous system: insomnia, nervousness, pacser (nonspecific), dyspnea; urogenital: impotence, polyuria

Other adverse reactions were reported sporadicaly with an incidence of $1.0 \%$ or less. These include: body as a whole/systemic lace edema, fever, hot flashes, malaise, periorbital edema, rigors; cardilovascular: arrhythmia, hypotension, increased angina, paroniria, tremor, vertipo; dermatologic: alopecia, increased sweating. urticaria, purpura; , gastrointestinal: eructation, gastrocoughing, epistaxis, upper respiratory tract infection, respiratony disorder, sinusitis; specialisensest: abnorma lacrimation, abn mal vision, taste perversion, tinnitus; urogentaliveproductive, breast pain, dysuria, hematuria, nocturia experience) where a causal relationship is uncertain gastrointestinal irritation, gastrointestinal bleeding. In multiple-dose U.S. and foreign controlled studies with nifedipine capsules in which adverse reactions were reported sponta. ment. Most were expected consequences of the vasodilator effects of Procardia. Adverse experiences reported in placebo-con trolled trials include: diziness, lightheadedness, and giddiness (27\%, compared to $15 \%$ placebo incidence); flushing, heat sensa-
tion (25\%, compared to $8 \%$ placebo incidence); headache $23 \%$, compared to $20 \%$ placebo incidence); weakness (12\%, compared to $10 \%$ placebo incidence): nausea, heartbum (11\%, compared to $8 \%$ placebo incidence): muscle cramps, tremor ( $8 \%$.

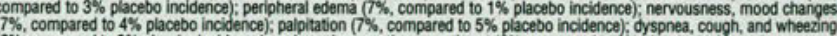
$6 \%$, compared to $3 \%$ placebo incidence); and nasal congestion, sore throat ( $6 \%$, compared to $8 \%$ placebo incidence). There is also a large uncontrolled experience in over 2100 patients in the United States. Most of the patients had vasospastic or resistant angina pectoris, and about half had concomitant treatment with

In addition, more serious adverse events were observed, not readily distinguishable from the natural history of the disease in these patients. It remains possible, however, that some or many of these events were drug related. Myocardial infarction duction disturbances each occurred in fewer than $0.5 \%$ of patients.

In a subgroup of over 1000 patients receiving Procardia with concomitant beta blocker theragy, the pattern and incidence of

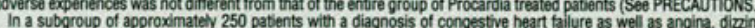

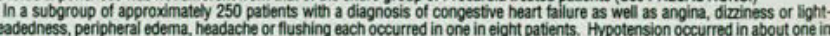
20 patients. Syncope occurred in approximately one patient in 250 . Myocardia infarction or symptoms of congestive heart tailure In occurred in about one patient in 15 . Atrial or ventricular dysithythmias each occurred in about one patient in 150 . 


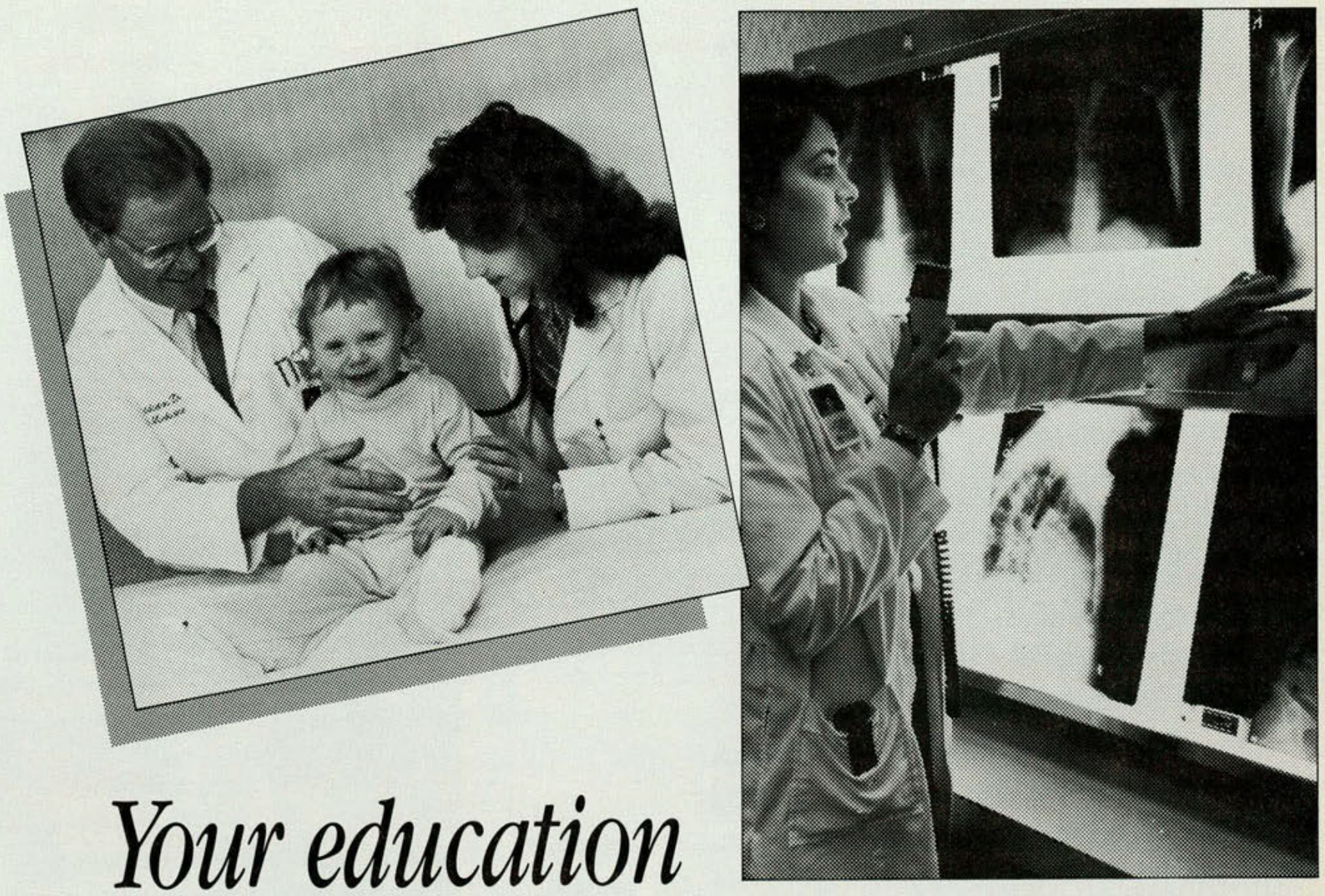

is important to us!

Left Pboto: Don Middleton, D.O., Resident, Tracy Middleton, D.O., Resident and "small" patient at FOH.

Right Pboto: Sucbeta Kulkarni, D.O., Intern

"Flint Osteopathic Hospital has provided acute and general health care for the Flint community for 50 years. The hospital is affiliated with Michigan State University and offers a full range of medical, surgical, emergency, and intensive care services. All medical and surgical subspecialties are covered. At FOH the intern and resident receives training in both outpatient ambulatory care as well as inpatient practices.

FOH, with 359 beds, is the largest osteopathic hospital in Michigan offering intern and residency training programs for osteopathic physicians. The medical education program is designed to provide a structured curriculum and experience in diagnosis and treatment. Morning reports and guest physician lectures occur daily. Reading lists and objectives have been developed for each service. A monthly journal club is conducted by each clinical department. EKG conferences are scheduled twice monthly. The FOH Congdon Lecture Series brings both D.O. and M.D. physicians to the hospital each month. Prominent practitioners, representative of both medical communities, share expertise in research findings during these monthly, day-long seminar presentations.

Ambulatory clinics have been established and provide longitudinal continuity training for interns and residents. Both traditional and alternative track internships are available at $\mathrm{FOH}$. The hospital is a charter member of the Consortium of Osteopathic Graduate Medical Education and Training (COGMET) in association with Michigan State University."

\section{Residencies}

- Anesthesia

- Family Practice

- Gastroenterology

- Internal Medicine

- Obstetrics/Gynecology

- Ophthalmology

- Orthopedics

- Otorhinolaryngology

- Pathology

- Pulmonary

- Radiology

- Surgery

- Urology

\section{Fellowships/Subspecialty} Residencies

- Medical Diseases of the Chest - Gastroenterology

One-year rotating internships Student externships

Christopher T. Meyer, D.O. Vice President of Medical Education

Dennis V. DeSimone, D.O. Director of Medical Education

(313) $762-4707$

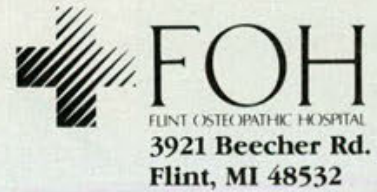

\section{Where family matters}




\section{The facts behind the Glucometer 3 \\ Diabetes Care System with Glucofilm Test Strips}

To make the right recommendation about a blood glucose monitoring system demands all the facts on reliability and ease of use. All the facts about the GLCOMEIER $^{*} 3$ Diabetes Care System and GLUCOFIM* Test Strips clearly make it the right system for more patients.

Fact: Provides accuracy for professionals, adds simplicity for patients.

A measuring range of $20-500$ $\mathrm{mg} / \mathrm{dL}$ assures you of clinically useful blood glucose results for good diabetes management. One-button operation, easy-tosee display and film-strip accuracy assure patients of simple, yet confident testing. In charts $A$ and $B$, our data from experienced evaluators and patients with diabetes who tested themselves support high-level accuracy for both groups. The close correlation of GLUCOMETER 3 System values. with the Yellow Springs Instrument (YSI) reference method shows this system is right for all.

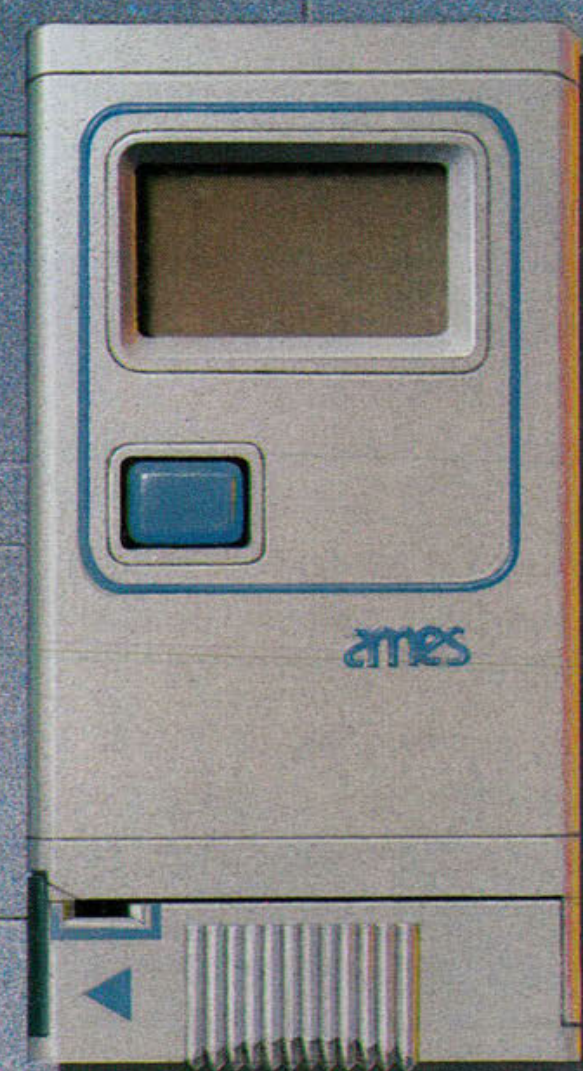

Fact: GLUCOFILM Test Strips provide the widest hematocrit range available for blood glucose levels from $20-500 \mathrm{mg} / \mathrm{dL}$.

Hematocrit levels from $20 \%$ to $60 \%$ have shown no significant effect on blood glucose results.

Fact: GLUCOMETER 3 Diabetes Care System is affordable.

Be your own judge of the facts behind this reliable, easy-touse and affordable blood glucose monitoring system. Contact your Miles Inc., Diagnostics Division representative or write us.
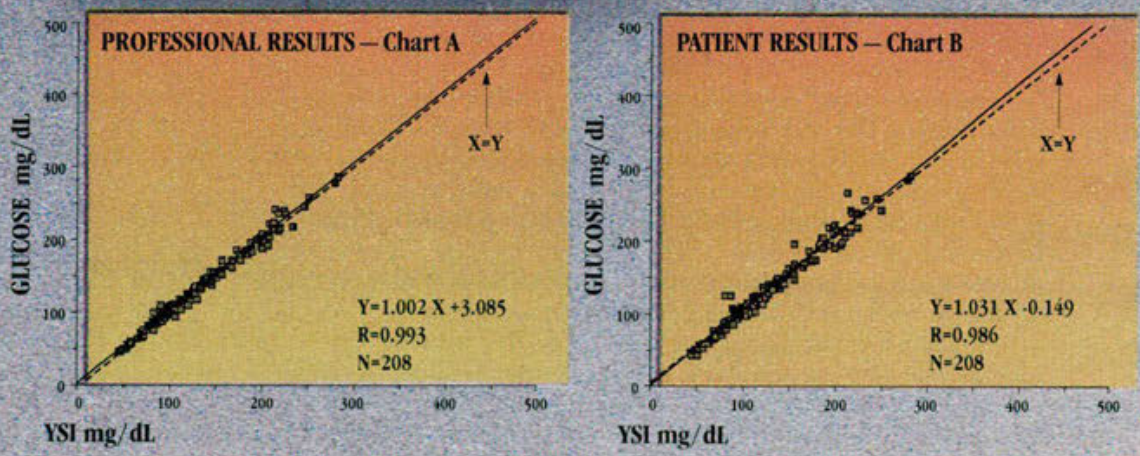

Miles Inc Diagnostics Division P.O. Box 70

Elkhart, IN 46515 